\title{
ANALISIS PENGARUH INFLASI DAN KURS TERHADAP INDEKS SAHAM SYARIAH INDONESIA (ISSI) TAHUN 2014-2018
}

\author{
Moh Syaiful Anwar ${ }^{1)}$ dan Adni Dwi A. ${ }^{2)}$ \\ ${ }^{12}$ Fakultas Eknomi dan Bisnis Islam, UIN Sunan Kalijaga Yogyakarta \\ e-mail1': syaifanwar98@gmail.com \\ e-mail²: adnikanzoe687@gmail.com
}

\begin{abstract}
The study aims to determine empirically the influence of inflation and exchange rates on the movements of the Indonesian Sharia stock index (ISSI). Research is conducted using quantitative research methods, with multiple linear regression analysis models. Data collection uses secondary data from the related data documentation. The data used is data from the monthly closing price of each company from 2014-2018 a number of 60 months. Research testing Using Test $T$ and test $F$ and processed using SPSS16. The results of the study showed that a partial rate variable showed a significant value of $0186>0.05$ making the relationship between the exchange rate and the movement of the ISSI value become unidirectional. As for the inflation variable up 1 level so the ISSI movement decreased-5,087. And simultaneously variable rates and inflation have a coefficient value of 0.323 or $31.3 \%$ so slight influence on ISSI movement.
\end{abstract}

Kata kunci: Inflasi, Kurs, Indeks Saham Syariah Indonesia (ISSI)

\section{PENDAHULUAN}

Investasi pada pasar modal syariah merupakan salah satu kegiatan ekonomi yang sedang berkembang di tataran masyarakat pada saat ini. Kegiatan investasi di pasar modal syariah menjadikan tempat yang mempertemukan pihak-pihak yang membutuhkan dana (emiten) dengan pihak-pihak yang kelebihan dana (investor) yang mana ini sesuai dengan korodor-koridor syariah. Pasar modal syariah adalah pasar modal yang dijalankan dengan ketentuan syariah (Sutendi, 2011).

Investasi syariah di pasar modal memiliki peranan untuk mengembangkan pangsa pasar industri keuangan syariah di Indonesia. Perkembangan pasar modal syariah di Indonesia semakin semarak dengan lahirnya Indeks Saham Syariah Indonesia (ISSI) yang diterbitkan oleh Bapepam LK dan Dewan Syariah Nasional Majelis Ulama Indonesia (DSN-MUI) pada tanggal 12 Mei 2011 (Sutendi, 2011). Indeks Saham Syariah Indonesia (ISSI) merupakan indeks saham syariah yang mana ini mencerminkan semua saham syariah yang ada di Bursa Efek Indonesia dan saham-saham tersebut telah terdaftar di Daftar Efek Indonesia (DES). BEI menjelaskan bahwa metode perhitungan indeks ISSI menggunakan rata-rata tertimbang dari kapitalisasi pasar.

Supramono (2014) menyatakan bahwa pergerakan harga di pasar saham sangat sulit ditebak. Saham terkenal dengan krakteristik "high risk-bigh return" yang merupakan surat berharga yang memiliki risiko tinggi tetapi memberikan peluang keuntungan yang tinggi pula. Saham memungkinkan pemodal mendapatkan return atau keuntungan (capital gain) dalam jumlah yang besar untuk jangka waktu yang cukup singkat (Qomariyah, 2018). 
Pergerakan harga saham yang tidak menentu dapat disebabkan oleh beberapa faktor ekonomi salah satunya adalah kurs dan inflasi. Inflasi merupakan salah satu gejala ekonomi yang menjadi perhatian bagi dunia usaha, bank sentral dan pemerintah. Pergerakan inflasi dapat memberikan pengaruh baik dan buruk terhadap dunia perekonomian tersbut. Semakin tinggi inflasi terjadi maka akan memberikan dampak negatif terhadap usaha ekonomi khususnya saham perusahaan (Nurwani, 2016).

Kurs / nilai mata uang suatu negara yang di badingkan dengan mata uang negara lain. Perubahan nilai kurs dapat memberikan pengaruh dalam biaya kompetitif perusahaan seperti pendapatan dan biaya operational. Fluktuasi yang terjadi pada nilai mata uang/kurs akan memberikan dampak pada harga saham perusahaan tesebut (Ilmi, 2017).

Bagi para investor sangat penting untuk mengetahui apakah fluktuasi inslasi dan kurs akan memberikan dampak yang positif maupun negatif terhadap harga saham perusahaan, khususnya saham syariah. Indeks Saham Syaiah Indonesia (ISSI) merupakan salah satu lembaga yang menggambarkan kinerja saham perusahaan secara menyeluruh, khususnya saham syariah pada Bursa Efek Indonesia.

Walaupun baru diluncurkan pada tahun 2011 return indeks saham syariah Indonesia mencatat penaikan tertinggi selama ISSI berjalan. Tercatat indeks saham syariah Indonesia mengalami kenaikan terbesar mencapai 28,1\% pada periode Juni 2016 - Juni 2017. Dalam jangka waktu 5 tahun nilai kapitalisasi pasar saham syariah juga meningkat 42\%. Pada tahun 2012, kapitalisasi pasar saham syariah baru mencapai Rp.2.451 triliun, tapi pada akhir September 2017 sudah menanjak menjadi Rp.3.473 triliun (Qomariyah, 2018).

\section{Gambar 1}

Grafik Indeks Saham Syariah Indonesia (ISSI) 2014-2018

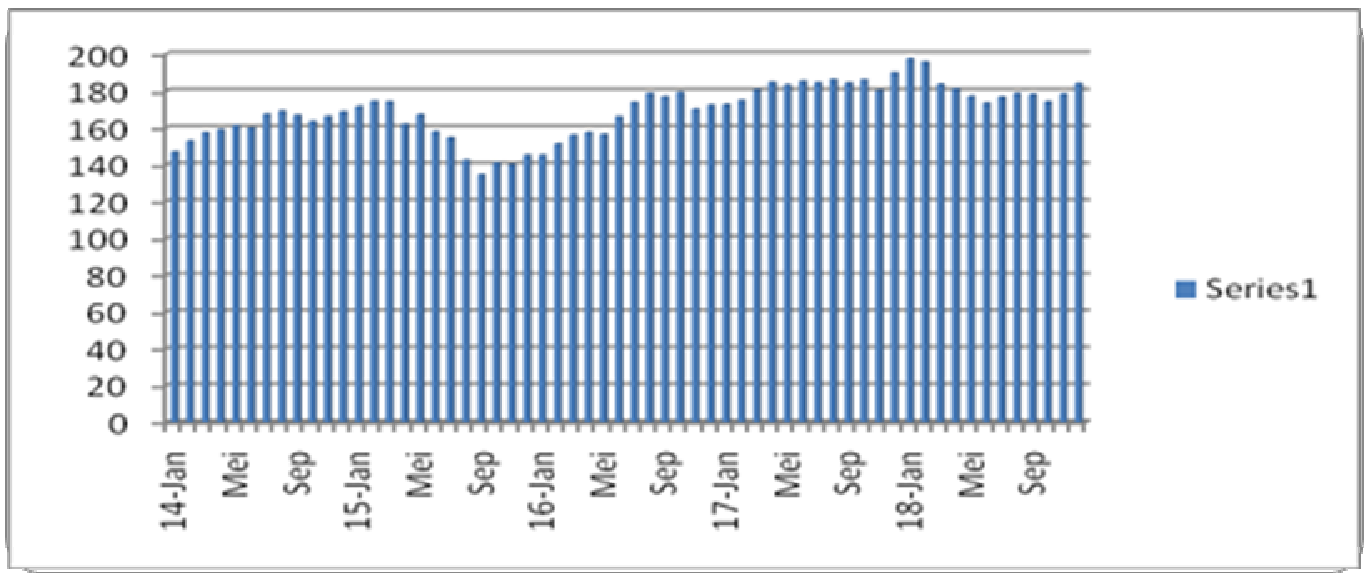

Sumber: Data diolah (2019)

Dari grafik diatas menunjukan bahwa nilai Indeks Saham Syariah Indonesia (ISSI) mengalami fluktuasi dari waktu ke waktu dengan cukup signifikan. Dilihat pada tahun 2014 sampai 2015 mengalami kenaikan yang cukup tinggi, namun pada tahun 2015 awal sampai 2015 September turun drastis. Tetapi pada bulan berikutnya naik kembali secara statis sampai pada tahun 2018.

Ekonomi makro merupakan sebuah lingkungan ekonomi yang kerap kali mempengaruhi operasi dan kinerja perusahaan sehari-hari. Bagi investor memiliki kemampuan dalam memahami dan meramlkan kondisi ekonomi makaro di masa 
mendatang akan bersdampak pada pembuatan keputusan yang menguntungkan. Oleh karena itu para investor seharusnya mempertimbangkan beberapa indikator ekonomi makro yang dapat membantu investor dalam menentukakn keputusan yang benar dan tepat. Indikator ekonomi makro yang seringkali dihubungkan dengan pasar modal adalah fluktuasi tingkat bungan, inflasi, kurs rupiah, dan pertumbuhan ekonomi (Kewal, 2012).

Perekonomian Indonesia selalu saja terpengaruh oleh keadaan ekonomi dunia. Penurunan dan pelemahan nilai tukar merupakan indikator makro ekonomi yang kerap kali mempengaruhi aktivitas ekonomi Indonesia.

Tingginya tingkat inflasi dapat menurunkan daya beli masyarakat dan juga meningkatnya harga faktor produksi. Hal itu biasanya akan berdampak pada anggapan buruk mengenai prospek perusahaan yang menghasilkan barang atau jasa yang terkena dampak inflasi sehingga dapat mempengaruhi penawaran harga saham perusahaan tersebut dan pada akhirnya berakibat pada pergerakan indeks harga saham di BEI (Kewal, 2012). Peningkatan inflasi yang relatif tinggi sangat berpengaruh negatif terhadap investor dipasar modal. Dengan kondisi inflasi yang tinggi membuat harga barang-barang pada umumnya memiliki kecenderungan untuk meningkat.

\section{Gambar 2}

Data Inflasi 2014 - 2018

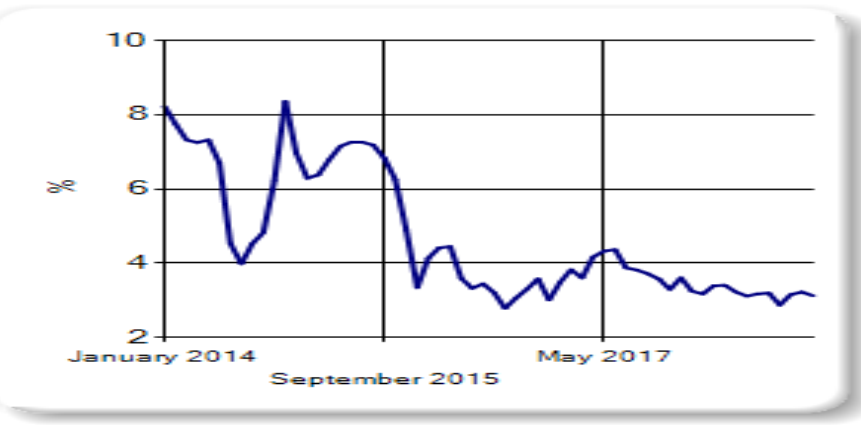

Sumber: data diolah (2019)

Dari grafik tingkat inflasi diatas bisa dilihat bahwa pada tahun 2014 tingkat inflasi berada dalam puncak tinggi akan tetapi pada tahun 2015 mengalami penurunan yang statis sampai pada tahun 2018.

Qomariyah (2018) meneliti pengaruh variabel inflasi, nilai tukar (Kurs), BI 7 day repo rate dan harga minyak dunia terhadap Indeks Saham Syariah Indonesia (ISSI) di Bursa Efek Indonesia. Hasil yang diperoleh dari penelitian ini dapat disimpulkan berdasarkan uji statistik variabel inflasi, nilai tukar (kurs), BI 7 day repo rate, dan harga minyak dunia secara bersama-sama (uji simultan-Uji F) memiliki pengaruh terhadap Indeks Saham Syariah Indonesia (ISSI). Berdasarkan uji t, variabel inflasi (X1) tidak memiliki pengaruh terhadap Indeks Saham Syariah Indonesia (ISSI) (Y), variabel nilai tukar (kurs) (X2) memiliki pengaruh negatif terhadap Indeks Saham Syariah Indonesia (ISSI) (Y). Saputra (2017) juga melakukan penelitian untuk menguji dan mengetahui pengaruh BI Rate, Inflasi, Nilai Tukar Rupiah dan Sertifikat Bank Indonesia Syariah (SBIS) Terhadap Indeks Saham Syariah Indonesia Periode Juni 2011 hingga Mei 2015. Dari hasil regresi linier berganda menunjukkan bahwa secara simultan keempat variabel independen mempengaruhi secara positif signifikan terhadap Indeks Saham Syariah Indonesia (ISSI) (Y) dan secara parsial hanya Nilai Tukar Rupiah (X3) yang berpengaruh positif signifikan terhadap Indeks Saham 
Syariah Indonesia (ISSI). Sari (2016) juga meneliti pengaruh variabel makroekonomi seperti nilai tukar, inflasi dan suku bunga terhadap harga saham perusahaan yang terdaftar di ISSI. Hasil penelitian ini menunjukkan bahwa variabel nilai tukar berpengaruh negatif dan variabel lain seperti inflasi dan suku bunga berpengaruh positif terhadap harga saham emiten di Indonesia.

Berdasarkan hasil penelitian yang berbeda dan uraian latar belakang diatas, penulis tertarik untuk melakukan pengujian kembali tentang pengaruh inflasi dan nilai tukar rupiah (kurs), terhadap Indeks Saham Syariah Indonesia (ISSI).

\section{METODE PENELITIAN}

Penelitian ini merupakan jenis penelitian kuantitatif dengan data pengamatan yang dilakukan dari tahun 2014 sampai tahun 2018. Data yang digunakan merupakan data sekunder yang mendukung variabel penelitian. Data dari variable independen dalam penelitian ini, yaitu: Inflasi, yang mana data ini penulis peroleh dari website Bank Indonesia. Variabel independen kedua ialah Kurs/nilai tukar, yang mana ini peneliti peroleh dari website Bank Indonesia. Adapaun variabel dependennya adalah Indeks Saham Syariah Indonesia (ISSI) yang diperoleh dari website investing.com. Semua data diambil dari harga penutupan bulanan masing-masing variabel dari tahun 2014-2018 dengan menggunakan data bulanan ( 60 bulan).

Analisis regresi berganda dilakukan untuk mengetahui pengaruh: Inflasi (X1) dan Nilai Tukar/Kurs (X2) terhadap Indeks Saham Syariah Indonesia (ISSI) (Y). Rumus regresi liniear bergada sebagai berikut:

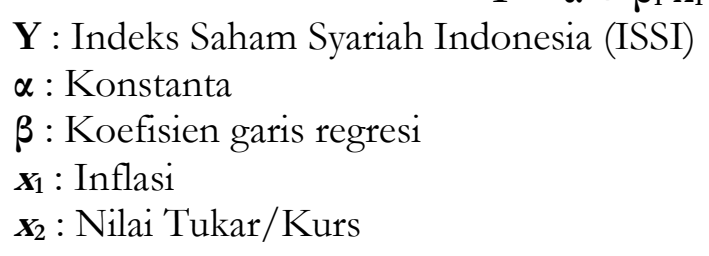

Pengujian hipotesis dalam penelitian ini menggunakan uji t dan uji $\mathrm{F}$ yang masingmasing pengujian dapat diuraikan sebagai berikut:

Uji t

Uji t atau uji signifikansi secara parsial digunakan untuk menguji apakah suatu variabel bebas (independen) berpengaruh atau tidak terhadap variabel terikat (dependen). Dalam penelitian ini, uji t digunakan untuk mengetahui pengaruh Inflasi (X1) dan Kurs (X2) secara parsial terhadap ISSI (Y). Menururt (Sujarweni, 2014), jika sig t $>0.05$ maka tidak ada pengaruh yang signifikan dan jika sig $\mathrm{t}<0.05$ maka ada pengaruh yang signifikan.

\section{Uji F}

Uji F disebut juga uji global atau uji signifikansi serentak dimaksudkan untuk melihat kemampuan menyeluruh dari variabel bebas dapat atau mampu menjelaskan tingkah laku atau keragaman variabel terikat (Suharyadi \& Purwanto, 2013).Uji F dalam penelitian ini dimaksudkan untuk melihat pengaruh Inflasi (X1) dan Kurs (X2) secara simultan atau bersamaan terhadap ISSI (Y). Jika nilai sig $>0.05$ maka tidak ada pengaruh yang signifikan. Jika nilai sig $<0.05$ maka terdapat pengaruh yang signifikan (Sujarweni, 2014). 


\section{HASIL DAN PEMBAHASAN}

Berdasarkan hasil pengujian menggunakan program SPSS diperoleh hasil sebagai berikut;

Tabel 1

Hasil uji t

\begin{tabular}{lrrrrrr}
\hline & \multicolumn{2}{c}{$\begin{array}{l}\text { Unstandardized } \\
\text { Coefficients }\end{array}$} & \multicolumn{2}{c}{$\begin{array}{c}\text { Unstandardized } \\
\text { Coefficients }\end{array}$} & & \\
\cline { 2 - 5 } Model & \multicolumn{1}{c}{ B } & \multicolumn{1}{c}{ Std. Error } & \multicolumn{1}{c}{ Beta } & \multicolumn{1}{c}{ t } & \multicolumn{1}{c}{ Sig. } \\
\hline 1 & (Constan) & 234.299 & 32.109 & & 7.297 & .000 \\
& Inflasi $\left(\mathrm{X}_{1}\right)$ & -5.636 & 1.108 & -.656 & -5.087 & .000 \\
& Kurs $\left(\mathrm{X}_{2}\right)$ & -.003 & .002 & -.173 & -1.339 & .186 \\
\hline
\end{tabular}

Sumber: data diolah (2019)

Berdasarkan tabel di atas, maka dapat diuraikan pengaruh masing-masing variabel inflasi dan kurs secara parsial terhadap ISSI.

\section{Pengaruh Inflasi terhadap ISSI}

Berdasarkan hasil analisis pada tabel 1 menunjukkan bahwa nilai signifikansi untuk inflasi $(\mathrm{X} 1)$ adalah sebesar 0.00 yang berarti sig t $(0.00)<0.05$. Hal tersebut menunjukkan bahwa inflasi (X1) secara parsial berpengaruh signifikan terhadap ISSI (Y). Hal ini sesuai dengan teori awal yang dikemukakan oleh Widjojo bahwa inflasi yang semakin tinggi akan semakin menurunkan tingkat profitabilitas perusahaan. Turunnya profit perusahaan adalah informasi buruk bagi para trader di bursa saham menyebabkan turunnya harga saham diperusahaan tersebut (Dwita \& Rahmidani, 2012). Hasil tersebut dikuatkan dengan penelitian yang dilaaukan oleh Ratna Sari (2016) yang menjelaskan adanya pengaruh yag signifikan dari inflasi terhadap pergerakan harga saham.

Namun, hasil tersebut berbanding terbalik dengan penelitian yang dilakukan oleh Qomariyah (2018), Saputra (2017) serta Widyasa dan Wirokinasih (2018) dimana tingkat inflasi tidak memberikan pengaruh yang signifikan terhadap pergerakan saham di ISSI. Selain menjadi salah saru penyebab pergerakan harga saham, inflasi juga menjadi resiko terhadap daya beli investor akan saham sebuah perusahaan. Apabila inflasi meningkat, investor akan menuntut tambahan premium inflasi untuk meningkatkan kompensasi yang diakibatkan adanya penurunan daya beli (Tandelilin, 2010).

\section{Pengaruh Kurs terhadap ISSI}

Berdasarkan data olahan pada tabel 1 menunjukkan nilai signifikansi untuk Kurs (X2) sebesar 0.186 yang berarti sig t $(0.186)>0.05$. Hal ini menunjukkan bahwa Kurs (X2) secara parsial tidak berpengaruh signifikan terhadap ISSI (Y). Hal ini sejalan dengan penelitian yang dilakukan oleh Sari (2016) dan Qomariyah (2018) yang menemukan bahwa Kurs tidak tidak berpengaruh terhadapa ISSI. Pernyataan ini sejalan dengan teori Tandelelin (2010) yang mengungkpakan bahwa nilai tukar memiliki kaitan dengan fluktuasi nilai tukar mata uang domestik dengan nilai mata uang negara lain. Akan tetapi ini juga berbanding terbalik dengan penelitian yang dilakukan oleh Saputra (2017) serta Widyasa dan Worokinasih (2018) yang menemukan bahwa ada pengaruh variabel Kurs teradap kinerja ISSI. Pengaruh tersebut dijelaskan Adiwarman dalam Saputra (2017) karena nilai tukar mata uang mampu mempresentasikan tingkat harga pertukaran dari satu mata uang ke mata uang negara lainnya dalam berbagai transaksi, termasuk investasi sehingga mampu memberikan pengaruh terhadap pergerakan harga saham. 
Kemudian untuk mengetahui pengaruh variabel inflasi dan kurs secara bersamasama terhadap ISSI diperoleh hasil sebagai berikut:

Tabel 2

Hasil uji F

\begin{tabular}{|c|c|c|c|c|c|c|}
\hline \multicolumn{2}{|c|}{ Model } & $\begin{array}{l}\text { Sum of } \\
\text { Square }\end{array}$ & df & & $\mathbf{F}$ & \multirow{2}{*}{$\begin{array}{l}\text { Sig. } \\
0000^{a}\end{array}$} \\
\hline 1 & Regression & 4185.884 & 2 & 2092.942 & 14.435 & \\
\hline & Residual & 8264.428 & 57 & 144.990 & & \\
\hline & Total & 12450.311 & 59 & & & \\
\hline
\end{tabular}

Sumber: data diolah (2019)

Berdasarkan hasil olahan diatas menunjukkan bahwa variabel inflasi dan kurs secara simultan berpengaruh terhadap Indeks Harga Saham Syariah (ISSI). Sesuai dengan nilai signifikasi 0,00 lebih kecil dari taraf signifikasi 0,05 . Nilai $F_{\text {hitung }} 14,435$ lebih besar dari $F_{\text {tabel }}$ 3,16 maka hasil analisis regresi signifikan.

Hasil perhitungan besarnya pengaruh secara simultan variabel inflasi dan kurs terhadap ISSI dapat dilihat pada tabel berikut.

Tabel 3

\section{Model Summary}

\begin{tabular}{ccccc}
\hline Model & R & R Square & $\begin{array}{c}\text { Adjusted R } \\
\text { Square }\end{array}$ & $\begin{array}{c}\text { Std. Error of the } \\
\text { Estimate }\end{array}$ \\
\hline 1 & .580 & .336 & .313 & 12.04118 \\
\hline
\end{tabular}

Sumber: data diolah (2019)

Nilai koefisien determinasi (Adjusted R Square) sebesar 0,313 atau 31,3\%. Nilai tersebut menunjukkan bahwa pergerakan ISSI pada periode 2014-2018 dipengaruhi oleh variabel Inflasi dan Kurs sebesar 31,3\%. Sedangkan sisanya 68,7\% dipengaruhi oleh variabel lain yang tidak di bahas dalam penelitian ini.

Hasil penelitian ini mendukung penelitian yang dilakukan oleh Widyasa dan Worokinasih (2018) serta Saputra (2017) yang mengungkapkan bahwa variabel inflasi dan kurs secara simultan memberikan pengaruh signifikan terhadap Indeks Harga Saham Syariah Indonesia (ISSI).

\section{KESIMPULAN}

Variabel Inflasi secara parsial berpengaruh signifikan terhadap pergerakan Indeks Saham Syariah Indonesia (ISSI). Hal ini ditunjukkan dengan nilai signifikansi sebesar 0.00 lebih kecil dari taraf signifikansi (0.05) dan nilai negatif sebesar -5.087 . Hasil penelitian ini menunjukkan bahwa hubungan antara Inflasi dan ISSI tidak searah, dimana ketika tingkat Inflasi naik 1 satuan, maka ISSI akan mengalami penurunan -5.087 poin. Ini menunjukkan bahwa Ha diterima dan $\mathrm{H} 0$ ditolak.

Variabel Kurs secara parsial tidak berpengaruh terhadap pergerakan Indeks Saham Syariah Indonesia (ISSI). Hal ini ditunjukkan dengan nilai signifikansi sebesar 0.186 lebih besar dari taraf signifikansi (0.05) dan nilai negatif sebesar -1.339. Hasil penelitian ini menunjukkan bahwa hubungan antara Kurs dan ISSI tidak searah, dimana ketika tingkat 
Inflasi naik 1 satuan, maka ISSI akan mengalami penurunan -5.087 poin. Ini menunjukkan bahwa $\mathrm{H} 0$ diterima dan $\mathrm{Ha}$ ditolak.

Hasil uji simultan (uji F) menunjukkan bahwa variabel tingkat inflasi, dan nilai tukar rupiah secara simultan berpengaruh signifikan terhadap Indeks Saham Syariah Indonesia (ISSI) periode 2014-2018 di Bursa Efek Indonesia (BEI). Hal ini ditunjukkan dengan nilai signifikansi sebesar 0,00 lebih kecil dari taraf signifikansi $(0,05)$, sehingga Ho ditolak dan Ha diterima. Nilai koefisien determinasi (Adjusted R Square) sebesar 0,313 atau 31,3\%. Nilai tersebut menunjukkan bahwa pergerakan ISSI pada periode 2014-2018 dipengaruhi oleh variabel Inflasi dan Kurs sebesar 31,3\%. Sedangkan sisanya 68,7\% dipengaruhi oleh variabel lain yang tidak dibahas dalam penelitian ini.

\section{SARAN}

Disarankan bagi peneliti lain yang hendak melakukan penelitian pada topik yang sama, sebaiknya menambahkan variabel lain yang sekiranya dianggap dapat mempengaruhi pergerkan ISSI, seperti tingkat suku bunga, jumlah uang beredar, harga emas dunia atau variabel makroekonomi lainnya. Selain menambahkan variabel diatas, peneliti juga dapat membandingkan pergerakan makroekonomi tersebut pada harga saham di ISSI dan IHSG. Dengan demikian penelitian selanjutnya dapat melibatkan variabel error lainnya yang sebesar $68,7 \%$. Selain itu, jumlah sampel dan periode penelitian agar lebih diperbanyak dan diperluas agar tingkat keakuratan penelitian semakin baik dan cakap.

Bagi investor yang akan melakukan transaksi saham syariah agar lebih mempertimbangkan informasi terkait kondisi makroekonomi yang terbaru terutama masalah tingkat inflasi dan tingkat kurs baik untuk domestik maupun asing.

\section{REFERENSI}

[1]. Dwita, V., \& Rahmidani, R. (2012). Pengaruh Inflasi, Suku Bunga dan Nilai Tukar terhadap Return Saham Sektor Restoran Hotel dan Pariwisata. Jurnal Kajian Manajemen Bisnis, 1(1), 59-74. https://doi.org/10.2403/jkmb.477000

[2]. Ilmi, M. F. (2017). Pengaruh Kurs/Nilai Tukar Rupiah, Inflasi dan Tingkat Suku Bunga SBI Terhadap Indeks Harga Saham Gabungan LQ-45 Periode 2009-2013. Jurnal Nominal, 4(1), 93-109.

[3]. Kewal, S. S. (2012). Pengaruh Inflasi, Suku Bunga, Kurs dan Pertumbuhan PDB Terhadap Indeks Harga Saham Gabungan. Jurnal Economia. Jurnal Ekonomia, 8(1), 53-64.

[4]. Nurwani. (t.t.). Analisis Pengaruh Inflasi, Nilai Tukar Rupiah dan Suku Bunga SBI Terhadap Pergerakan Indeks Harga Saham (IHSG) di Bursa Efek Indonesia. Jurnal UMSU, 16(6). https://doi.org/10.30596/ekonomikawan.v16i2.945

[5]. PT Bursa Efek Indonesia. (2018). PT Bursa Efek Indonesia. http://www.idx.co.id

[6]. Qomariyah, S. (2018). Pengaruh Inflasi, Nilai Tukar (KURS), BI 7 Day Repo Rate, dan Harga Minyak Dunia Terhadap Indeks Saham Syariah Indonesia (ISSI) Tahun 2014-2017. IAIN Surakarta.

[7]. Rahmawati, M., \& Laili, N. (2015). Faktor Makroekonomi yang Mempengaruhi Pergerakan Harga Saham Pada Ideks Saham Syariah Indonesia (ISSI) di Bursa Efek Indonesia (BEI). 2(11), 928-942. 
[8]. Saputra, R. (2017). Pengaruh BI Rate, Inflasi, Nilai Tukar Rupiah dan Sertifkat Bank Indonesia Syariah (SBIS) Terhadap Indeks Saham Syariah Indonesia (ISSI). UIN Raden Fatah Palembang.

[9]. Sar, R. (2016). Pengaruh Nilai Tukar Rupiah, Inflasi dan Suku Bunga Terhadap Harga Saham pada Perusahaan yang Terdaftar di ISSI. Artikel Ilmiah, 1-14.

[10]. Suharyadi, \& Purwanto. (2013). Statistika untuk Ekonomi dan Keuangan Modern. Jakarta: Salemba Empat.

[11]. Sujarweni, W. (2014). SPSS Untuk Penelitian. Yogyakarta: Pustaka baru Press.

[12]. Sutendi, A. (2011). Pasar Modal Syariah. Yogyakarta: Pustaka baru Press.

[13]. Tandelilin, E. (2010). Portofolio dan Investasi Teori dan Aplikasi. Kanisius.

[14]. Widyasa, V. I., \& Wirokimasih, S. (2018). Pengaruh Tingkat Inflasi, Nilai Tukar Rupiah, dan Tingkat Suku Bunga Domestik Terhadap Indeks Saham Syariah Indonesia (ISSI) (Studi Pada Saham Syariah Yang Terdaftar Di Bursa Efek Indonesia Periode 2013- 2017). Jurnal Administrasi Bisnis (JAB), 60(1), 119-128. 